\title{
A CROSS SECTIONAL STUDY ON THE DEFINITE DIAGNOSIS OF TUBERCULOUS PLEURAL EFFUSION AT GULAB DEVI CHEST HOSPITAL.
}

1. M.Phil (Microbiology) University of Health Science, Lahore.

2. M.Phil Molecular Biology Gulab Devi Educational Complex, Gulab Devi Hospital, Lahore, Pakistan.

3. FCPS (Cardiology) Associate Professor Department of Cardiology Al-Aleem Medical College, Gulab Devi Teaching Hospital Lahore.

4. PhD Molecular Biology Associate Professor Department of Molecular Biology Al-Aleem Center for Advance Studies and Research Gulab Devi Hospital, Lahore.

Correspondence Address: M. Umair Hanif

Department of Molecular Biology Al-Aleem Center for Advance Studies and

Research Gulab Devi Hospital, Lahore. umair.hanif@gdec.edu.pk

Article received on:

14/09/2018

Accepted for publication: 04/02/2019

Received after proof reading: $31 / 07 / 2019$

\section{INTRODUCTION}

Pleural effusion is an abnormal collection of fluid in the pleural space. It is the most prominent feature of pleural disease, with causes including cardiopulmonary diseases, inflammation and malignant diseases requiring urgent diagnosis. ${ }^{1}$ There are two types of pleural effusions, transudative and exudative. ${ }^{2,3}$ If the ratio of pleural fluid protein to serum protein level is $<0.5$ then it is transudative pleural effusion which results due to changes in hydrostatic forces, with capillary permeability remaining normal. ${ }^{4}$ Exudative pleural effusion have ratio of $>0.5$ and are caused by either increased capillary permeability and lymphatic obstruction or inflammation. ${ }^{5}$

Pleural effusion is not a rare etiology in

\begin{abstract}
Ghazala Riaz', Madiha Naheed², M. Imran Hanif ${ }^{3}$, M. Umair Hanif ${ }^{4}$
TRACT... Establishing the definite causative etiology of pleural effusion is often quite mandatory before the start of any anti tuberculosis therapy. The present study was aimed to differentiate among different causes of pleural effusion in suspected TB patients. Study Design: Cross sectional study. Setting: A cross sectional study was carried out at Gulab Devi Chest 作 and Methods: Pleural effusion was aspirated by the registered clinician and the sample was processed for cytology, relative density, culture and PCR. Results: Total of $\sim 10 \%$ patients were patient tool for MTB. MTB is the major cause of pleural effusion in our studied population but other efficacy of the PCR should be tested on larger population and a definite diagnosis should be
\end{abstract} Key words: $\quad$ PCR, Pseudomonas, MTB, Staphylococcus, ZN Stain

Article Citation: Riaz G, Naheed M, Hanif MI, Hanif MU. A cross sectional study on the definite diagnosis of tuberculous pleural effusion at Gulab Devi Chest Hospital. Professional Med J 2019; 26(8):1339-1344.

DOI: 10.29309/TPMJ/2019.26.08.3880

pulmonary tuberculosis (TB) and it is often associated with disease severity and difficulty in diagnosis. Pakistan is ranked fifth with among countries which have high prevalence of pleural TB. ${ }^{6}$ The frequency of pleural effusion in TB patients was approximately $31 \% .{ }^{7}$ Pleural effusions can also occurs as a result of infections other than TB, so the definitive diagnosis and etiology of the pleural effusion is mandatory before the start of therapy. Furthermore, previous reports showed that $40 \%$ of the cases with bacterial pneumonia have an associated para pneumonic effusion. Bacteria often cause exudative pleural effusions and include Streptococcus pneumonia, Staphylococcus aureus and gram negative organisms such as E.coli and Pseudomonas. ${ }^{8}$ 
Definite and rapid diagnosis of extra pulmonary tuberculosis is very difficult due topaucibacillary nature of pleural effusion since conventional techniques have limitations. ${ }^{9}$ Smear examination of pleural fluid requires mycobacterium tuberculosis (MTB) concentrations of $10,000 / \mathrm{mL}$, so smearing of pleural effusion for diagnosis of TB has very low sensitivity(0 to $1 \%$ ). Diagnostic value of culture is $12-70 \%$ in the most precise studies and is generally considered as gold standard ${ }^{10}$ but culture of pleural fluid requires 2 to 6 weeks for confirmation of MTB. ${ }^{11}$ This again imposes restriction on the early and definite diagnosis of pleural effusion.

In the past few decades nucleic acid amplification tests like Polymerase Chain Reaction (PCR) had greatly improved the diagnosis of many infectious diseases in terms of time and accuracy. PCR detects the genomes of the invading organisms in biological samples with high sensitivity and specificity. But the efficiency of PCR in MTB detection from pleural fluid has been reported with variable sensitivity (20-90\%) and specificity (70-100\%) among different research groups and laboratories. ${ }^{12}$ Various factors has been reported to effect the sensitivity of the PCR like quantity of mycobacterium, their nonrandom distribution, the presence of inhibitors, the kind of primer used and the genomic sequence which is amplified. ${ }^{13}$

Therefore, this study has two main objectives; first to determine the exact causative etiology of the pleural effusions and differentiate between Gram positive, Gram negative and MTB by culture and confirmation of MTB by PCR. Second, to find the sensitivity and specificity of PCR in pleural effusion of MTB against the smearing.

\section{MATERIAL AND METHODS}

The cross sectional study was designed and conducted at Gulab Devi Chest Hospital, Lahore after written approval from the ethics committee and informed consent of the patients. The duration of the study was seven months and carried out from $1^{\text {st }}$ September 2014 to $31^{\text {st }}$ March 2015. Non probability sampling was done and a questionnaire was designed to record the clinical findings and family history of the patients.
32 patients were selected on the basis of inclusion criteria which includes, patients having pleural effusion with unknown etiology, patients having pleural effusion with other chronic infection, injury, with previous diagnosis. Patients not having pleural effusion and getting treatment of pleural effusion were excluded.

A total of $45 \mathrm{ml}$ of effusion sample was aspirated by a registered clinician and divided it into three portions. One portion of $20 \mathrm{ml}$ was used for gram culture and cytology, $10 \mathrm{ml}$ for MTB culture and smear, $15 \mathrm{ml}$ of pleural fluid was used to perform $\mathrm{PCR}$. Total protein and relative mass density was determined using refract meter.

Culturing of gram positive and negative bacteria was done by streaking method according to the guidelines. The initial processes in MTB culture was homogenization and decontamination by Modified Petroff's method in which $4 \%$ sodium hydroxide is used. ${ }^{14}$ After centrifugation, the sediment was re-suspended in 1.0 to $1.5 \mathrm{ml}$ of sterile phosphate buffer ( $\mathrm{pH}$ 6.8). This suspension was then used for inoculation of Lowenstein Jensen Culture medium(Merck Catalogue \# 105400) which contain malachite green, glycerol, asparagine, potato starch and coagulated eggs. Plates were incubated at humidified chamber without $\mathrm{CO}_{2}$ at $37^{\circ} \mathrm{C}$ for up to 4 weeks.

For total cell count, cells were counted using improved Neubaur Counting Chamber. One part of pleural fluid was diluted with two parts of Toluidine blue in 1:2 ratio. Counting chamber was filled with fine bore pipette and cells were allowed to settle down for 2 minute. All stained white cells in 5 large squares were counted and multiply by dilution factor and expressed as cell count per liter of pleural fluid.

For the DNA extraction "Cinnagen Co. (DNG^^ TM - Plus) Kit was used. $15 \mathrm{ml}$ of the effusion sample was centrifuged to pallet down any suspensions and cells. Then manufacture's protocol was followed and briefly described here.100 $\mu$ of concentrated sample was mixed with $400 \mu$ of pre warmed extraction buffer and vortexed for 15-20 seconds. DNA was precipitated by $300 \mathrm{ul}$ 
of isopropanol centrifuged at $12000 \mathrm{rpm}$ for 10 minutes and supernatant was discarded. The pallet was washed with $70 \%$ ethanol and dried at $65^{\circ} \mathrm{C}$ for 5 minutes. Final Pallet was re-suspended in Tris EDTA (TE) buffer pH 7.5 and store at $-20^{\circ} \mathrm{C}$ until further use.

The PCR reaction contains, 8 pmoles of each primer, PCR buffer(1X), $\mathrm{MgCl}_{2}(1.5 \mathrm{mM})$, dNTPs $(250 \mu \mathrm{M})$ and TAQ DNA Polymerase (1U) in the final reaction volume of $20 \mu \mathrm{l}$. Forward (GCAACCTTGGGAACAATACG) and reverse (CCACGTTGTCCATGAAGAGG) primer used were designed by Primer3 webserver against the MTB insertion sequence. The cycling conditions consist of initial denaturation at $95^{\circ} \mathrm{C}$ for $5 \mathrm{~min}$ followed by 35 cycles of denaturation at $95^{\circ} \mathrm{Cfor} 30$ seconds, annealing at $54^{\circ} \mathrm{Cfor}$ 30 seconds, extension at $72^{\circ} \mathrm{Cfor} 30$ seconds and final extension at $72^{\circ} \mathrm{Cfor} 5$ minutes. After amplification, 10ul was taken from each PCR product and loaded on $2 \%$ Agarose gel containing ethidium bromide and visualize under UV. Bands corresponding to $163 \mathrm{bp}$ size marker and positive MTB DNA were considered positive. A negative control was also run containing no sample but only buffer to validate the reaction.

Smearing were performed for all samples and examined at the Gulab Devi Chest Hospital's Microbiology Laboratory for the presence of AFB. Standard protocol for Ziehl-Neelsen (ZN) staining was followed and examined under light microscope.
The data analysis was done with SPSS version 16. Mean, range and standard deviations were used to present quantitative data by the simple descriptive analysis.

\section{RESULTS}

Mean age of study population was $34.47+15.29$ years. Out of total 32 patients, $13(40.62 \%)$ were females and 19 (59.38\%) were males (Table-l). The mean lymphocyte, protein and WBC count was $96.8750+9.33 \%, 5.2969+1.78 \mathrm{~g} / \mathrm{dl}$ and $265.75+185.3810^{\times 3} / \mu \mathrm{l}$ respectively (Table-l). The mean of fluid quantity was $1.6372+2.26 \mathrm{ml} /$ $\mathrm{kg}$. Blood ESR had mean value of $45.3125+3.42$ $\mathrm{mm} /$ hour. Blood urea had mean37.7812+1.34 $\mathrm{mg} / \mathrm{dl}$. The mean value of neutrophil count was $1.4062+7.95 \%$. RBC count had mean $30.6250+1.31$.

For division according to the nature of the effusion, 30 (93.75\%) patients were with exudative pleural effusion whereas, only $2(6.25 \%)$ have transudative pleural effusion. In this study, 2 patients were staphylococcus aureus positive, 1 was pseudomonas positive and 29 had shown no growth on culture for pseudomonas and $\mathrm{S}$. aureus. Two samples which show growth for MTB in culture also test positive for MTB DNA by PCR whereas, one sample was PCR positive but culture negative. In 6 MTB culture positive samples PCR did not detect MTBDNA (Table-II). The comparison of PCR with smear and culture of pleural effusion show that all samples were smear negative while 2 were positive by PCR out of 8 MTB culture positive samples.

\begin{tabular}{|l|c|c|c|c|}
\hline & N & Minimum & Maximum & Mean \pm Std. Deviation \\
\hline Age & 32 & 11 & 70 & $34.47 \pm 15.291$ \\
\hline Lymphocyte count & 32 & 60.00 & 100.00 & $96.87 \pm 9.33170$ \\
\hline Protein & 32 & .10 & 9.00 & $5.2969 \pm 1.77918$ \\
\hline Specific Gravity & 32 & 1.02 & 1.07 & $1.0428 \pm 0.01042$ \\
Blood urea & 32 & 15.00 & 65.00 & $37.7812 \pm 1.341341$ \\
\hline WBC count & 32 & 92.00 & & \\
Neutrophil count & 32 & .00 & 455.00 & $265.7500 \pm 185.38626$ \\
RBC count & 32 & .00 & 710.0 & $1.4602 \pm 7.95495$ \\
ESR & 32 & 14.00 & 120.00 & $40.6250 \pm 1.300812$ \\
Fluid quantity & 32 & & 1000.00 & $1.63725 \pm 3.42434$ \\
& & & \\
\hline
\end{tabular}




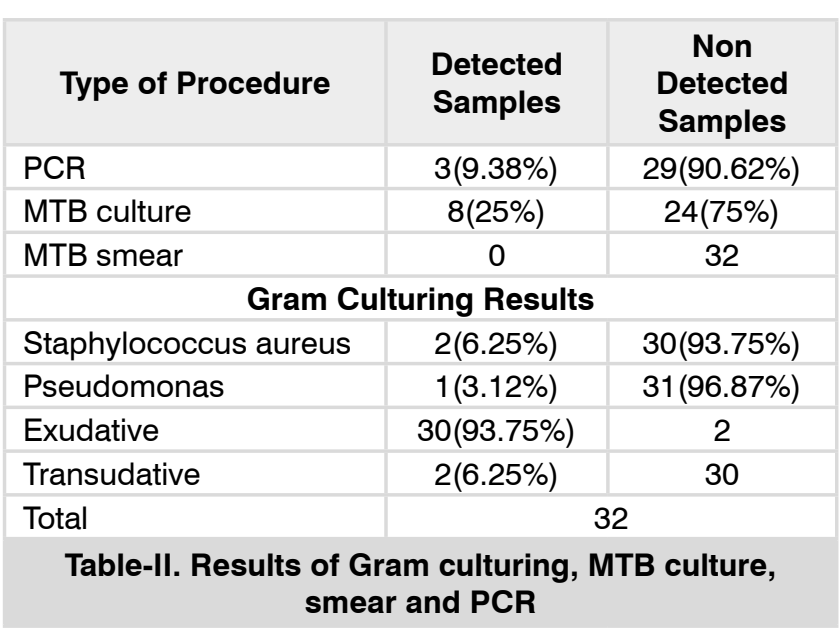

In this study the sensitivity and specificity of PCR was found to be $25.00 \%$ and $95.83 \%$ respectively in comparison to smearing along with the positive predictive value of $66.67 \%$ and negative predictive value of $79.31 \%$ (Table-III). Sensitivity, specificity, positive predictive value and negative predictive value were calculated according to following formulas.

Sensitivity $=\frac{a}{a+b}$

Specificity $=\frac{d}{c+d}$

Positive Predictive Value $=\frac{a}{a+c}$

Negative Predictive Value $=\frac{d}{b+d}$

\begin{tabular}{|l|c|c|}
\hline \multicolumn{1}{|c|}{ Statistic } & PCR & Smear \\
\hline Sensitivity & $25.00 \%$ & $50.00 \%$ \\
\hline Specificity & $95.83 \%$ & $50.00 \%$ \\
\hline Positive Predictive Value & $66.67 \%$ & $25.00 \%$ \\
\hline Negative Predictive Value & $79.31 \%$ & $75.00 \%$ \\
\hline
\end{tabular}

Table-III. Sensitivity and specificity of PCR and smear

\section{DISCUSSION}

In this study pleural effusion analysis was done in total 32 patients and the results showed the male gender predominate with $59.38 \%$. Same result of male pre-dominancy was found in a study conducted by Einarsson et al. in 2003. ${ }^{15}$ Exudative pleural effusions are more common than the transudative and is more helpful in diagnosing the etiology of the specimen. This study (93.75\%) and various previous studies reported the same high percentage of the exudative effusion among the selected patients. ${ }^{16}$

In this study 8 (25.00\%) patients had tuberculosis pleural effusion, $2(6.25 \%)$ were with malignant pleural effusion and $3(9.375 \%)$ patients were with gram positive staphylococcus aureus and gram negative pseudomonas infection. Previously in one of the study malignancy is more common cause of pleural effusion than tuberculosis. ${ }^{17}$ Thus our study is in discordant in this respect, as in our settings tuberculosis is more common cause. This might be due to the difference in the inclusion criteria and the patients enrolled in the study.

Lymphocytosis with significantly increased total white cell count was observed in tuberculous pleural effusion. ${ }^{18}$ With lymphocyte count of more than $90 \%$ there are more chances of lymphomaand tuberculosis. ${ }^{19}$ Results of this study showed that the lymphocyte count and TLC was high in maximum patients. This lymphocytosis can be a helpful marker in defining the etiology of the exudative pleural effusion but it cannot be used as a sole marker in defining the cause of the pleural fluid.

In this study PCR was used to detect MTB from pleural effusion which was either culture positive or negative. Two samples were test positive by PCR which was culture positive and one culture negative sample was also test positive by PCR for MTB DNA. This might be due to non-random distribution or very low yield of the mycobacterium in the sample, as culture requires a minimum threshold of bacteria for growth (10-100 live bacilli) whereas PCR can detect and amplify the single copy of the genome but it cannot differentiate between active or latent infection. This can be achieved by comparing the results of PCR with clinical symptoms and other diagnostic tests like culture and radiological findings. The detection of MTB by PCR in smear and culture negative cases assumes a lot of clinical significance, because these cases can be treated for TB if have clinical symptoms. Whereas, in the absence of PCR one would have to wait for 6 weeks in case of culture or rely on non-specific findings to made a treatment 
regime. ${ }^{20}$ MTB smear had specificity $50.00 \%$ as compared to PCR specificity $95.83 \%$. Direct smearing of pleural fluid have least diagnostic value because of the need of 10,000 bacilli per $\mathrm{ml}$ of fluid.

These results showed that PCR had high specificity $(95 \%)$ as compared to smear. In this study all samples of pleural effusion were smear negative. So it may be concluded thatsmear is fast and easy but often produces false negative results for extra-pulmonary $\mathrm{TB}(21)$. The positive and negative predictive values observed in this study shows thatNAA tests have high specificity and positivelikelihood ratios. ${ }^{22}$

\section{CONCLUSION}

In conclusion tuberculosis is major cause of pleural effusion but there is also some percentage of gram positive and gram negative bacteria that is not negligible. According to this research, PCR can be used as specific and reliable test for the diagnosis of TB. However a combination of conventional methods and nucleic acid amplification test must be applied for the rapid and initial diagnosis of tuberculosis in paucibacillary specimens like pleural effusion.

The major limitation of the study is the small sample size of the population. The results of this study should be validated on larger sample size to standardize the specificity and sensitivity of the PCR.

\section{ACKNOWLEDGEMENT}

The authors acknowledge the help provided from the microbiology and histopathology department for providing the facility to carry out necessary analysis of the samples.

\section{Conflict of Interest}

The authors declare no conflict of interest in any circumstances.

Copyright@ 04 Feb, 2019.

\section{REFERENCES}

Daniele V. Natural resources and the 'quality'of economic development. The Journal of Development Studies. 2011 Apr 1;47(4):545-73.
2. Thomas R, Lee YC. Causes and management of common benign pleural effusions. Thorac Surg Clin. 2013;23(1):25-42, v-vi. Epub 2012/12/05.

3. Ault MJ, Wittnebel KD. Use of Ultrasound for Removal of Tunneled Drainage Catheters. Proceedings of UCLA Healthcare. 2014;18.

4. Chetty KG. Transudative pleural effusions. Clin Chest Med. 1985;6(1):49-54. Epub 1985/03/01.

5. Light RW, Macgregor MI, Luchsinger PC, Ball WC. Pleural effusions: the diagnostic separation of transudates and exudates. Annals of internal medicine. 1972;77(4):507-13.

6. Kiran S, Jabeen KJ, Irfan M. Tuberculous Pleural Effusion: An Update. Pakistan Journal of Chest Medicine. 2015;20(1).

7. Rehan M, Alam MT, Imran K, Farrukh SZ-U-I, Masroor $M$, Kumar P. The Frequency of Various Diseases in Patients Presenting with Pleural Effusion. Gomal Journal of Medical Sciences. 2013;11(1).

8. Chapman SJ, Davies RJ. Recent advances in parapneumonic effusion and empyema. Curr Opin Pulm Med. 2004;10(4):299-304. Epub 2004/06/29.

9. Chakravorty S, Sen MK, Tyagi JS. Diagnosis of extrapulmonary tuberculosis by smear, culture, and PCR using universal sample processing technology. Journal of Clinical Microbiology. 2005;43(9):4357-62.

10. Ruan SY, Chuang YC, Wang JY, Lin JW, Chien JY, Huang CT, et al. Revisiting tuberculous pleurisy: pleural fluid characteristics and diagnostic yield of mycobacterial culture in an endemic area. Thorax. 2012;67(9):822-7. Epub 2012/03/23.

11. Peter IG, van Zyl—Smit RN. Diagnosis of TB: state of. European Respiratory Monograph 58: Tuberculosis. 2014;58:124.

12. Hasaneen NA, Zaki ME, Shalaby HM, El-Morsi AS. Polymerase chain reaction of pleural biopsy is a rapid and sensitive method for the diagnosis of tuberculous pleural effusion. CHEST Journal. 2003;124(6):2105-11.

13. Gopi A, Madhavan SM, Sharma SK, Sahn SA. Diagnosis and treatment of tuberculous pleural effusion in 2006. Chest. 2007;131(3):880-9. Epub 2007/03/16.

14. Satapathy P, Das D, Murmu BN, Kar SK. Decontamination of sputum for longer time in sodium hydroxide for isolation of Mycobacterium tuberculosis. Int $\mathrm{J}$ Mycobacteriol. 2014;3(4):290-2. Epub 2016/01/21. 
15. Einarsson JG, Isaksson HJ, Guethmundsson G. [Closed needle pleural biopsy in Iceland 1990-1999.]. Laeknabladid. 2003;89(3):215-9. Epub 2006/07/05.

16. Ercan S, Davutoglu V, Altunbas G, Inanc IH, Kaplan M, Oylumlu $\mathrm{M}$, et al. Prognostic role of incidental pleural effusion diagnosed during echocardiographic evaluation. Clin Cardiol. 2014;37(2):115-8. Epub 2014/01/09.

17. Porcel JM, Esquerda A, Vives M, Bielsa S. Etiology of pleural effusions: analysis of more than 3,000 consecutive thoracenteses. Archivos de Bronconeumología (English Edition). 2014;50(5):161-5.

18. Frank W. Tuberculous pleural effusion: INTECH Open Access Publisher; 2013.
19. Porcel JM, Light RW. Diagnostic approach to pleural effusion in adults. Am Fam Physician. 2006;73(7):121120. Epub 2006/04/21.

20. Christina S, Nishanthini A, Kumar S. PCR in the differential diagnosis of Tuberculosis: A comparative study. International Multidisciplinary Research Journal. 2011;1(6).

21. Munir M, Shabbir I, Iqbal R, Khan SU, Syed ZA. Diagnosis of extra-pulmonary tuberculosis: conventional versus newer methods. Pak J Chest Med. 2009;15:11-4.

22. Kashyap RS, Rajan AN, Ramteke SS, Agrawal VS, Kelkar SS, Purohit HJ, et al. Diagnosis of tuberculosis in an Indian population by an indirect ELISA protocol based on detection of Antigen 85 complex: a prospective cohort study. BMC Infect Dis. 2007;7(1):74. Epub 2007/07/11.

\section{AUTHORSHIP AND CONTRIBUTION DECLARATION}

\begin{tabular}{|c|l|l|}
\hline Sr. \# & \multicolumn{1}{|c|}{ Author-s Full Name } & \multicolumn{1}{|c|}{ Contribution to the paper } \\
\hline 1 & Ghazala Riaz & Sampling and Experiments. \\
2 & Madiha Naheed & $\begin{array}{l}\text { Experimental work and data } \\
\text { analysis. } \\
\text { Manuscript writing and proof } \\
\text { reading. }\end{array}$ \\
\hline 4 & M. Imran Hanif & $\begin{array}{l}\text { M. Umair Hanif } \\
\text { Study design, Supervision } \\
\text { manuscript writing and proof } \\
\text { reading. }\end{array}$ \\
\hline
\end{tabular}

